Article

\title{
Key Findings from the European Men-Who-Have-Sex-With-Men Internet Survey in Greece
}

\author{
Katerina Pantavou ${ }^{1}$, Georgios Tsiakalakis ${ }^{2}$, Sophocles Chanos ${ }^{2}$, Georgios Polkas ${ }^{3}$, Georgios Papageorgiou ${ }^{2}$, \\ Nicolaos Dedes ${ }^{2}$, Axel J. Schmidt ${ }^{4}$ and Georgios K. Nikolopoulos ${ }^{1, *}$ (D) \\ 1 Medical School, University of Cyprus, 2029 Nicosia, Cyprus; pantavou.katerina@ucy.ac.cy \\ 2 Ath Checkpoint, 10554 Athens, Greece; gtsiakalakis@positivevoice.gr (G.T.); schanos@athcheckpoint.gr (S.C.); \\ gpapageorgiou@positivevoice.gr (G.P.); nikos.dedes@positivevoice.gr (N.D.) \\ 3 Thess Checkpoint, 54635 Thessaloniki, Greece; gpolkas@thesscheckpoint.gr \\ 4 Sigma Research, London School of Hygiene and Tropical Medicine, London WC1H 9SH, UK; \\ axel.j.schmidt@emis-project.eu \\ * Correspondence: nikolopoulos.georgios@ucy.ac.cy; Tel.: +357-2289-5223
}

Citation: Pantavou, K.; Tsiakalakis,

G.; Chanos, S.; Polkas, G.;

Papageorgiou, G.; Dedes, N.; Schmidt,

A.J.; Nikolopoulos, G.K. Key Findings

from the European

Men-Who-Have-Sex-With-Men

Internet Survey in Greece.

Epidemiologia 2021, 2, 114-123.

https://doi.org/10.3390/

epidemiologia2010010

Academic Editors: Masoud Dara and Francisco José Nunes Antunes

Received: 21 December 2020

Accepted: 11 March 2021

Published: 17 March 2021

Publisher's Note: MDPI stays neutral with regard to jurisdictional claims in published maps and institutional affiliations.

Copyright: (c) 2021 by the authors. Licensee MDPI, Basel, Switzerland. This article is an open access article distributed under the terms and conditions of the Creative Commons Attribution (CC BY) license (https:// creativecommons.org/licenses/by/ $4.0 /$ )

\begin{abstract}
The European Men-Who-Have-Sex-With-Men Internet Survey (EMIS-2017) is an international survey for men who have sex with men (MSM) designed to measure the level and distribution of four dimensions: (a) sexual health outcomes, (b) risk and precaution behaviors, (c) health promotion needs, and (d) coverage/uptake of interventions. The aim of the current work is to provide an overview of key demographics and findings for MSM in Greece covering the abovementioned dimensions of EMIS-2017, especially regarding HIV. Overall, 2909 men met the inclusion criteria for the analysis. The participants' age ranged between 15 and 74 years old (median 35 years). According to the descriptive analysis, $14.4 \%$ of the participants reported moderate and $8.9 \%$ severe anxiety and depression. The self-reported HIV prevalence was 11\%. A high number of participants had non-steady male partners $(74 \%, n=2153)$. The number of non-steady intercourse partners in the last 12 months was over two for about $61.5 \%(n=1321)$ of the participants. A very small number of participants had ever tried to get pre-exposure prophylaxis $(\operatorname{PrEP})(2.2 \%, n=63)$, and $41.2 \%$ of the participants $(n=1199)$ were unaware of PrEP. About half of the participants $(51.6 \%, n=1501)$ did not know that vaccination against both hepatitis A and B viruses is recommended for MSM. The results of EMIS-2017 identify important needs and can help policy making and prevention planning.
\end{abstract}

Keywords: EMIS-2017; MSM; Greece; online survey; HIV; sexually transmitted infections; PrEP; PEP

\section{Introduction}

Men who have sex with men (MSM) are disproportionally affected by the human immunodeficiency virus (HIV) [1]. In Europe in particular, male-to-male sex is the predominant mode of HIV transmission [2]. Moreover, sexually transmitted infections (STIs) other than HIV, such as chlamydia, gonorrhea, and syphilis, continue to rise [3], affecting men who have sex with men (MSM) quite often [4]. In this context, the European Men-WhoHave-Sex-With-Men Internet Survey (EMIS-2017) was conducted aiming at collecting data useful for the planning of HIV and STI prevention and care programs, and the monitoring of national progress in this area [5].

EMIS-2017 was funded by the European Commission Health Programme 2014-2020 and supported by PlanetRomeo, European AIDS Treatment Group (EATG), Eurasian Coalition on Male Health (ECOM), European Centre for Disease Prevention and Control (ECDC), European Monitoring Centre for Drugs and Drug Addiction (EMCDDA), and European Commission (DG SANTE). EMIS-2017 was coordinated by Sigma Research at the London School of Hygiene and Tropical Medicine (LSHTM) in association with the Robert Koch Institute (RKI) in Berlin. The survey was conducted in 50 countries collecting data of 144,305 individual responses. More than 100,000 men in the European Union (EU) took 
part, in addition to more than 6000 in European Free Trade Association (EFTA) countries, and about 7000 in countries in the EU Enlargement Area or the European Neighborhood Policy. Moreover, 6000 MSM were recruited in Russia, 6000 in Canada, and 3500 in the Philippines [6].

The aim of this work is to describe key data collected in EMIS-2017 for Greece: sample population, morbidities and especially HIV infection, people's behaviors that cause (risks) or protect them (precautions) from morbidities, opportunities, capabilities and motivations for risk and precaution behaviors, and actions of others that meet or undermine the needs of MSM.

\section{Materials and Methods}

EMIS-2017 (website: www.emis2017.eu (accessed on 11 March 2021)) was a multilanguage, internet-based survey for MSM living in Europe or in a limited number of countries outside Europe. The survey was conducted in 33 languages using a multilingual online questionnaire [7] and used similar recruitment procedures across countries. It was promoted via international (and to a much smaller extent national) MSM dating apps and websites as well as via civil society organizations, such as Positive Voice. EMIS-2017 used a convenience sample following a non-probability sampling method and focusing on MSM who have access to the internet and/or use gay dating apps.

EMIS-2017 was approved by the ethics committee of the London School of Hygiene and Tropical Medicine (University of London). All participants in EMIS-2017 were asked to confirm that they consent to participate. Details on the design and methods used in EMIS-2017 can be found in the article of Weatherburn and colleagues [8].

EMIS-2017 was carried out simultaneously in 50 countries, including Greece, from 18 October 2017 to 31 January 2018. Eligible participants in the Greece survey were men: (a) living in Greece, (b) at or over the age of homosexual consent (i.e., 15 years), (c) who are sexually attracted to men and/or had sex with men, and (d) who reported that they understand the nature and purpose of the study and consent to take part. The participants were asked to self-complete a questionnaire in the language of their choice, and they could withdraw at any time.

\subsection{Study Area}

Greece is a Mediterranean country in Southeastern Europe. The population is approximately 10.8 million (males, 5.3 million) based on the 2011 census [9]. The nation's capital, Athens, is the largest and most populous area of the country with 3.8 million residents [9].

Lesbian, gay, bisexual, and transgender (LGBT) culture is vibrant in several neighborhoods of Athens, in the second largest city of Greece, Thessaloniki, as well as on some Greek islands. Homosexual activity has been legal in Greece since 1951. Antidiscrimination laws in employment were enacted in 2005, and civil unions were legislated in 2015. The HIV epidemic has been mainly concentrated in MSM with the exception of 2011-2013, when an outbreak among people who inject drugs occurred (PWID) [10]. The cumulative number of HIV diagnoses (including AIDS cases) reported in Greece by 31 December 2017 was 16,669 (males: $82.84 \%, n=13,808$ ) [11]. After excluding cases with undocumented mode of HIV transmission, $57.8 \%(n=8.076)$ of HIV diagnoses in Greece were in MSM [11].

\subsection{Questionnaire}

The questionnaire used in EMIS-2017 [7] was developed in English and then translated to Greek. A manual of the variables in the questionnaire [12] is also available at the EMIS2017 website. Some slang terms were included in parentheses in order to increase responses to questions regarding socially "undesirable" behavior [4]. The EMIS-2017 questionnaire was based on a previous version of the survey, EMIS-2010 [13].

Questionnaire items were divided in five sections: (a) "Demographics", (b) "Morbidities", (c) "Behaviours", (d) "Needs", and (e) "Interventions". The "Demographics" section collects information on key characteristics of the participants (i.e., gender identity, 
sex at birth, age, country of birth, length of residents' stay in a given country, education, employment, sexual attraction, sexual identity, and outness). The "Morbidities" section includes items about both psychological and physical health and focuses on mental health problems among MSM (i.e., anxiety and depression, suicidal ideation, alcohol dependency) and on sexually transmitted infections (i.e., HIV, hepatitis, syphilis, gonorrhea chlamydia, and anogenital warts). Two measures of mental health were used, the Patient Health Questionaire-4 (PHQ-4) for anxiety and depression [14] and the four CAGE questions for alcohol use [15]. The "Behaviours" section collects information on activities of participants that could contribute to or detract from morbidities. It includes items about sexual health risk (having sex, taking drugs, and doing them together) and precaution behavior (taking antiretroviral drugs or HIV chemoprophylaxis and being vaccinated). The "Needs" section focuses on commonly unmet sexual health needs of the MSM population that could inform the design of interventions. The Intervention section refers to actions of people that meet (positive intervention) or undermine (negative intervention) the health promotion needs of MSM. Positive interventions include education, health and social services and negative interventions include homophobic legislation, exclusion, and abuse.

\subsection{Statistical Analysis}

Mean and median values and standard deviation and interquartile range were used to describe continuous variables. Frequencies and percentages were used for categorical variables. The statistical analysis was conducted in Stata v. 14 (Stata Corp., College Station, TX, USA).

\section{Results}

In EMIS-2017, 2943 individual cases were recorded as participants living in Greece. Of these, 34 failed to meet the following inclusion criteria: (a) identified as men or trans men $(n=24)$, (b) sexually attracted to men and/or having had sex with men $(n=8)$, and (c) at or over the age of homosexual consent in Greece $(n=2)$, leaving a sample of 2909 records qualified for the study.

\subsection{Sample Description}

Of the 2909 men included in the analysis, $1 \%(n=28)$ identified as trans and $0.1 \%$ $(n=3)$ reported that the gender they were assigned at birth was female (decline to state, $n=1$; not answered, $n=5,0.2 \%$ ) (Table 1 ). The age of the participants ranged between 15 and 74 years (Figure $\mathrm{S1}$ ). The median age was 35 years (interquartile range: $27-42$ ).

Table 1. Current gender identity, sex at birth, country of birth $(n=2909)$, and length of residence in Greece $(n=261)$.

\begin{tabular}{|c|c|c|c|c|c|c|c|}
\hline & & $N$ & $\%$ & & & $N$ & $\%$ \\
\hline Gender & Man & 2881 & 99.0 & \multirow{4}{*}{$\begin{array}{l}\text { Sex Assigned } \\
\text { at Birth }\end{array}$} & Male & 2900 & 99.7 \\
\hline Identity & Trans man & 28 & 1.0 & & Female & 3 & 0.1 \\
\hline \multirow{5}{*}{$\begin{array}{l}\text { Country of } \\
\text { Birth }\end{array}$} & Greece & 2646 & 91.0 & & Refuse to state & 1 & 0.0 \\
\hline & Germany & 72 & 2.5 & & Not answered & 5 & 0.2 \\
\hline & Cyprus & 38 & 1.3 & \multirow{6}{*}{$\begin{array}{c}\text { City of } \\
\text { Residence }\end{array}$} & Athens & 1413 & 48.6 \\
\hline & Other & 146 & 5.0 & & Thessaloniki & 422 & 14.5 \\
\hline & Not answered & 7 & 0.2 & & Other settings (population & 900 & 30.9 \\
\hline \multirow{3}{*}{$\begin{array}{c}\text { Years of } \\
\text { Residence in } \\
\text { Greece }^{1}\end{array}$} & $<1$ & 10 & 3.8 & & under 500,000) & & \\
\hline & $1-5$ & 43 & 16.4 & & $\begin{array}{c}\text { Other settings (populations } \\
\text { over } 500,000)\end{array}$ & 36 & 1.2 \\
\hline & $>5$ & 203 & 77.9 & & Not answered & 138 & 4.7 \\
\hline
\end{tabular}

${ }^{1}$ Question shown when the answer to question regarding the country of birth was other than Greece.

The majority of men $(91 \%, n=2646)$ reported that they were born in Greece (Table 1). Most men not born in Greece had been living in Greece for more than 10 years (73.2\%, $n=191$ ). More than $60 \%$ of the participants reported that they had spent over 6 years in full-time education since the age of $16(60.2 \%, n=1752)$, that they were employed 
full-time, part-time or were self-employed $(65.9 \%, n=1916)$, and that their feelings about their income these days were neither comfortable nor struggling or that they were living comfortably / really comfortably $(72.4 \%, n=2160)$ (Table S1).

Almost three quarters of men thought of themselves as gay or homosexual $(72.2 \%$, $n=2099)$ and $15.1 \%(n=440)$ as bisexual (Table S2). The percentage of men that were out about their sexual attraction to men was limited; $32.7 \%(n=941)$ reported that few people know and $12.9 \%(n=371)$ reported that no one knows that they are attracted to men (Table S2). About one third of men currently had a steady partner $(29.8 \%, n=867)$, and $15.5 \%(n=450)$ reported that they had never had a steady relationship (Table S3). Paying for sex $(20.3 \%, n=590)$ was more common than being paid for sex $(11.3 \%, n=328)$ (Table S4).

\subsection{Morbidities and Health Outcomes}

\subsubsection{Mental Health}

Anxiety and depression of $23.3 \%(n=679)$ of participants was "moderate" $(14.4 \%$, $n=420)$ or "severe" $(8.9 \%, n=259)$ (Table 2 and Table S5). The most common bothering problem was feeling nervous, anxious or on the edge (46.8\%, $n=1361$; Table S5). Over the last 2 weeks, $18.3 \%(n=533)$ of the respondents had been bothered by thoughts that they would be better off dead, or of hurting themselves in some way (Table 2). The CAGE screening tool [15] showed that $289(9.9 \%)$ of the men in the survey met the criteria for potential alcohol dependency (Table 2). Most positive responses on alcohol dependency were reported on the questionnaire item asking participants whether they had tried to cut down on their drinking $(23.3 \%, n=602$; Table S6).

Table 2. Mental health, suicidal ideation, and alcohol dependency $(n=2909)$.

\begin{tabular}{|c|c|c|c|c|c|}
\hline & $\begin{array}{c}\text { Normal } \\
(0-2)\end{array}$ & $\begin{array}{l}\text { Mild } \\
(3-5)\end{array}$ & $\begin{array}{c}\text { Moderate } \\
(6-8)\end{array}$ & $\begin{array}{l}\text { Severe } \\
(9-12)\end{array}$ & Not Answered \\
\hline Anxiety and depression score (PHQ-4) ${ }^{1}$ & $\begin{array}{c}1116 \\
(38.4)\end{array}$ & $\begin{array}{c}1055 \\
(36.3)\end{array}$ & $\begin{array}{c}420 \\
(14.4)\end{array}$ & $\begin{array}{c}259 \\
(8.9)\end{array}$ & $\begin{array}{c}59 \\
(2.0)\end{array}$ \\
\hline \multirow{2}{*}{$\begin{array}{c}\text { Over the last } 2 \text { weeks, how often have } \\
\text { you been bothered by thoughts that you } \\
\text { would be better off dead, or of hurting } \\
\text { yourself in some way? }\end{array}$} & Not at all & Some days & $\begin{array}{l}\text { More than half } \\
\text { the days }\end{array}$ & Nearly every day & Not answered \\
\hline & $\begin{array}{c}2355 \\
(81.0)\end{array}$ & $\begin{array}{c}392 \\
(13.5)\end{array}$ & $\begin{array}{c}73 \\
(2.5)\end{array}$ & $\begin{array}{c}68 \\
(2.3)\end{array}$ & $\begin{array}{c}21 \\
(0.7)\end{array}$ \\
\hline \multirow[b]{2}{*}{ Alcohol dependency (CAGE) ${ }^{2}$} & Yes & No & Not answered & & \\
\hline & $\begin{array}{l}289 \\
(9.9)\end{array}$ & $\begin{array}{c}2560 \\
(88.0)\end{array}$ & $\begin{array}{c}60 \\
(2.1)\end{array}$ & & \\
\hline
\end{tabular}

${ }^{1}$ Patient Health Questionaire-4 (PHQ-4) [14]; ${ }^{2}$ CAGE questions for alcohol use [15].

\subsubsection{Sexually Transmitted Infections}

Overall, $11 \%$ of the participants reported an HIV diagnosis (Figure 1a). Of those, $7.2 \%$ $(n=23)$ had been diagnosed within the last 12 months (Figure 1b). Moreover, most of them had an undetectable viral load $(73 \%, n=233)$. The most common infection was that with human papillomavirus (HPV). About 23.5\% $(n=684)$ of the participants reported that they had been diagnosed with anogenital warts in their lifetime (Figure 1a), and 3.9\% ( $n=27)$ of them had first been diagnosed within the last 12 months (Figure 1b). Diagnoses of syphilis and gonorrhea were reported by $9 \%(n=261)$ and $12.4 \%(n=361)$ of the participants, respectively. Of these men, $37.9 \%(n=99)$ had been diagnosed with syphilis and $18.3 \%$ $(n=66)$ with gonorrhea in the last 12 months. The most common STI within the last 12 months was syphilis (Figure 1b). 


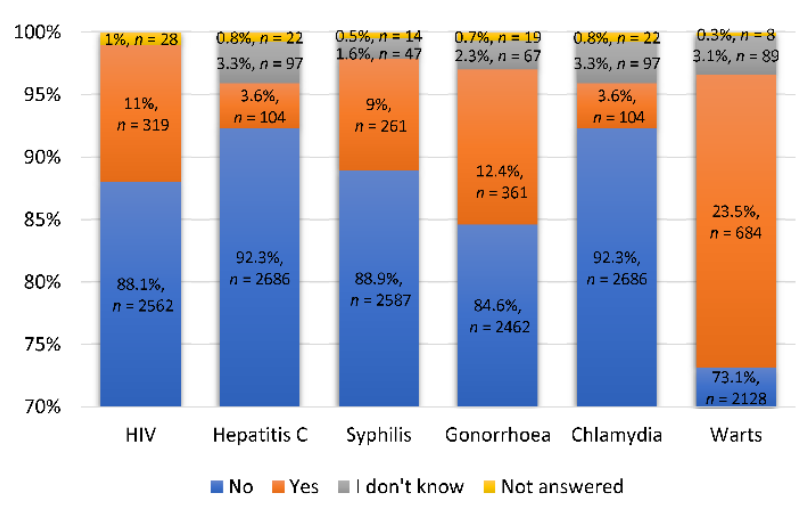

(a)

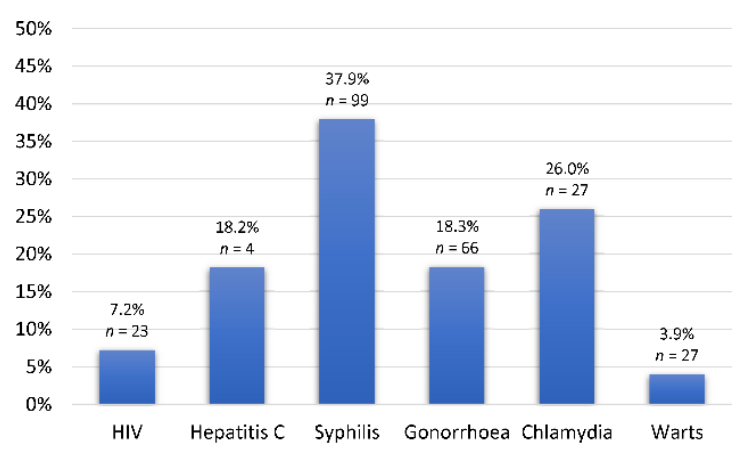

(b)

Figure 1. Diagnoses of sexually transmitted infections. The participants self-reported (a) whether they had ever been diagnosed with HIV, hepatitis C, syphilis, gonorrhea, chlamydia or anogenital warts and (b) whether they had been diagnosed with HIV, syphilis, gonorrhea, chlamydia or whether they were first diagnosed with hepatitis C or anogenital warts within the last 12 months.

\subsection{Risk and Precaution Behavior \\ 3.3.1. Sex and Drugs}

There were men participating in EMIS-2017 who had never had sexual contact or intercourse with another man. Table S7 shows that $2.9 \%(n=85)$ of men had never had any kind of sex with a man and $7.3 \%(n=212)$ had never had any intercourse. One in ten reported that the first time they had any sex with another male they were 13 years old or younger than $13(11 \%, n=310)$, and $27.5 \%(n=775)$ when they were between 14 and 17 years old. About $74 \%(n=2153)$ of the participants had non-steady male partners and $8.1 \%(n=153)$ never used or used seldom condoms when they had intercourse with non-steady male partners. About $61.5 \%(n=1321)$ reported 3 or more non-steady male partners in the last 12 months (Table S7).

The most commonly used substance was alcohol; $91.2 \%(n=2653)$ of the respondents had consumed alcohol in their lifetime and $59.7 \%(n=1736)$ within the last seven days (Figure S2). Alcohol consumption was followed by use of tobacco products; $68.7 \%(n=2003)$ had used tobacco in their lifetime. Another two substances used by about $30 \%$ of the participants were poppers and cannabis. Sex under intoxication was reported by $40.9 \%$ $(n=1098)$ of men in the last 12 months (Table S8).

\subsubsection{Antiretroviral Treatment (ART), HIV Chemoprophylaxis, and Vaccination}

Among men who had been diagnosed with HIV, 87.6\% $(n=304)$ reported that they had taken antiretroviral treatment (ART) (Table 3). Of those, $98 \%(n=298)$ were receiving ART at the time the survey was conducted (Table 3 ). Among men without an HIV diagnosis, $7.9 \%(n=203)$ had tried to get post-exposure prophylaxis (PEP), of whom $66 \%(n=134)$ had taken one or more than one course of pills (Table 3). Pre-exposure prophylaxis (PrEP) was reportedly taken by $0.9 \%$ of the participants $(n=27)$. 
Table 3. Seeking and uptake of antiretroviral treatment (ART), post-exposure prophylaxis (PEP), and pre-exposure prophylaxis $(\mathrm{PrEP})$.

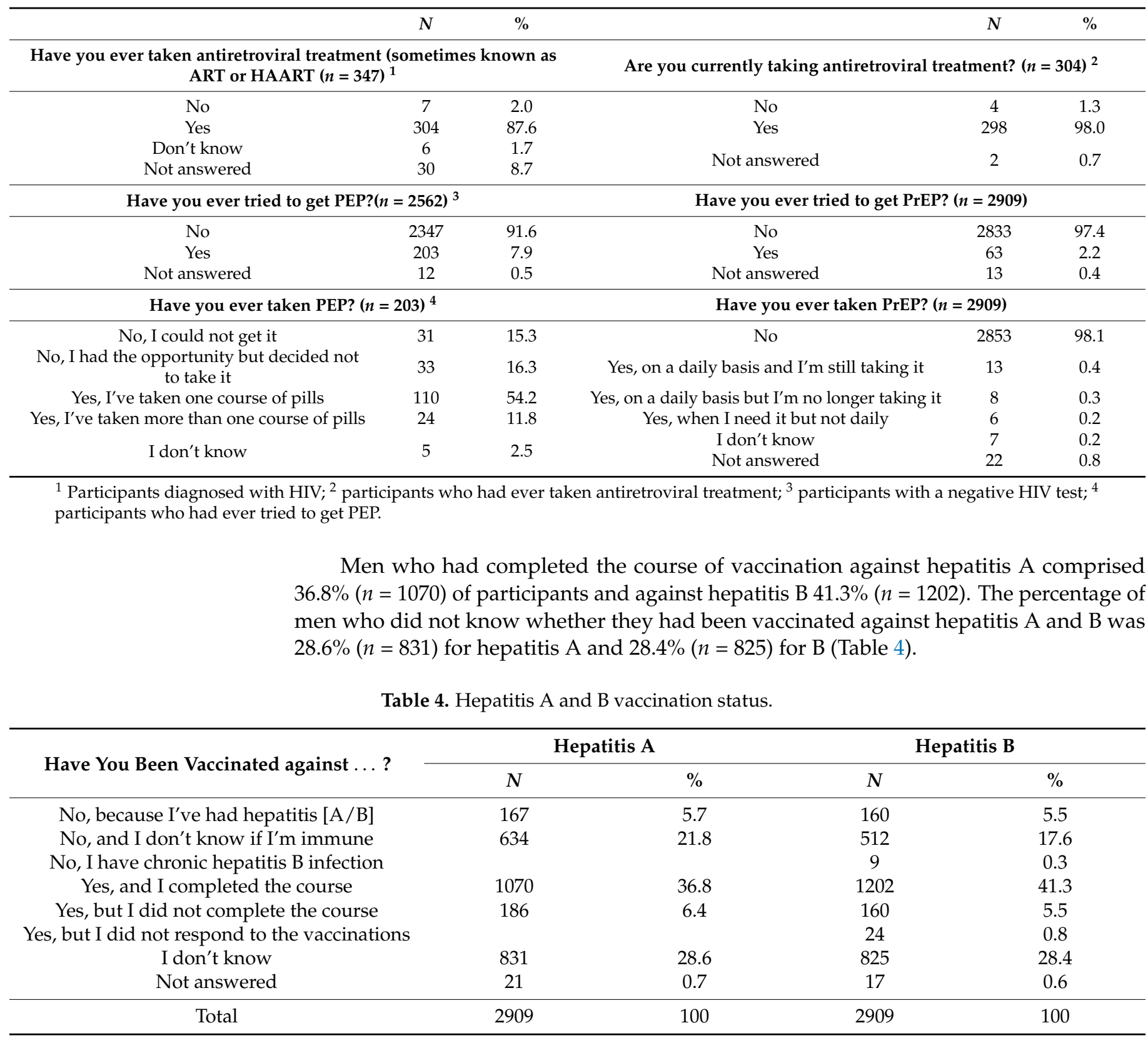

\subsection{Needs}

Considering self-efficacy for safe sex, $22.7 \%(n=661)$ of men did not agree with the statement "The sex I have is always as safe as I want it to be". Slightly fewer, $16.3 \%$ $(n=472)$, did not find it easy to say "no" to sex they do not want (Table S9). Self-reported knowledge of HIV was high. Over $93 \%$ of men reported that they already knew the facts included in the questionnaire items related to the general knowledge of HIV (Table S10), $83 \%$ about HIV transmission, and $90.4 \%$ about HIV testing. Fewer respondents knew that a person with HIV who is on effective treatment cannot pass their virus to someone else during sex $(50 \%, n=1466)$.

More participants reported that they had not heard of $\operatorname{PrEP}(41.2 \%, n=1199)$ than that they had not heard of PEP $(33.9 \%, n=987)$ (Table 5A). The low level of knowledge of PEP and PrEP was also observed when men were asked to report whether they already know basic facts on PEP and PrEP (Table S11). The percentage of participants who already knew 
basic information related to PEP ranged from $39.8 \%$ to $56.4 \%$ and related to PrEP from $13 \%$ to $46.3 \%$. Among men not diagnosed with HIV, 58.4\% $(n=1496)$ reported that they were quite or very confident that they could get PEP if they thought they needed it (Table 5B). Moreover, $42.5 \%(n=1089)$ responded that they would likely use PrEP if it was available and affordable to them (Table 5B).

Table 5. (A) Awareness of post-exposure prophylaxis (PEP) and pre-exposure prophylaxis (PrEP) $(n=2909)$ and (B) Confidence accessing PEP among men not diagnosed with HIV and certainty of intention to use PrEP $(n=2562)$.

\begin{tabular}{|c|c|c|c|c|c|c|}
\hline & & $N$ & $\%$ & & $N$ & $\%$ \\
\hline A & Have you heard of ... & PEP & & & PrEP & \\
\hline & No & 987 & 33.9 & & 1199 & 41.2 \\
\hline & Yes & 1587 & 54.6 & & 1409 & 48.4 \\
\hline & Not sure & 303 & 10.4 & & 254 & 8.7 \\
\hline & Not answered & 32 & 1.1 & & 47 & 1.6 \\
\hline B & \multicolumn{3}{|c|}{$\begin{array}{c}\text { How confident are you that you could get PEP if you } \\
\text { thought you needed it? }\end{array}$} & \multicolumn{3}{|c|}{$\begin{array}{l}\text { If PrEP was available and affordable to you, } \\
\text { how likely would you be to use it? }\end{array}$} \\
\hline & Very confident & 815 & 31.8 & Very unlikely & 460 & 18.0 \\
\hline & Quite confident & 681 & 26.6 & Quite unlikely & 238 & 9.3 \\
\hline & A little confident & 425 & 16.6 & Not sure & 771 & 30.1 \\
\hline & Not at all confident & 299 & 11.7 & Quite likely & 449 & 17.5 \\
\hline & I don't know & 337 & 13.2 & Very likely & 640 & 25.0 \\
\hline & Not answered & 5 & 0.2 & Not answered & 4 & 0.2 \\
\hline
\end{tabular}

The proportion of "already know" responses in the four out of five facts given for hepatitis ranged between $71.3 \%(n=2073)$ and $89 \%(n=2589)$ (Table S12). The most common unknown fact was that doctors recommend that MSM should be vaccinated against both hepatitis $\mathrm{A}$ and hepatitis $\mathrm{B}$ viruses $(51.6 \%, n=1501)$. The proportion of participants who could benefit from hepatitis A and B vaccination (i.e., men non-vaccinated against hepatitis or who have not completed the course of vaccinations or who were aware of their hepatitis vaccination status) and actually knew where to get vaccinated against hepatitis A or B was $36.3 \%(n=600)$ or $36.2 \%(n=551)$, respectively (Table S12).

\subsection{Interventions}

In the last 12 months, $23.7 \%(n=689)$ of the participants had been stared at or intimidated, $14.9 \%(n=433)$ had had verbal insults directed to them, and $1.6 \%(n=46)$ had been punched, hit, kicked, or beaten because someone knew or presumed they were attracted to men (Table S13). One third $(38.6 \%, n=1122)$ of the participants reported that they had received free condoms from gay or HIV organizations, saunas, clinics, bars or clubs in the last 12 months, and $71.2 \%(n=2072)$ had bought condoms at a physical store (not online) (Table S14).

About $11.4 \%(n=330)$ of men reported that someone had ever spoken to them personally at a health service in Greece about PrEP (mainly at checkpoints, i.e., community centers for HIV and hepatitis B and C prevention and testing commonly collaborating with healthcare foundations and governmental organizations, $n=271)$, and $72.8 \%(n=2120)$ reported that they had seen or heard any information about HIV or STIs specifically for MSM in the last 12 months (Table S15). One fifth of men who had been diagnosed with HIV $(20.7 \%, n=66)$ were dissatisfied or very dissatisfied with the support and information they had received when they were diagnosed HIV positive (Table S16).

\section{Discussion}

This work provides an overview of the data collected in Greece in the context of EMIS2017. The dataset for Greece consisted of 2909 participants with a median age of 35 years, mainly homosexual $(72.2 \%)$, born in the country $(91 \%)$, with over 6 years of full-time education since the age of $16(60.2 \%)$, and a satisfactory self-perception of financial status 
(72.4\%). These attributes were similar to those of participants from other countries involved in EMIS-2017 [5]. Outness and steady partnerships seem to be limited among MSM in Greece. In particular, less than half of the participants (39\%) reported that people in their social network were aware of the participants' attraction to men. This was lower than the reported percentage (58.8\%) in the EMIS-2017 European report [5]. Steady partnerships of the MSM participants in Greece were less frequent $(29.8 \%)$ than those reported by all participants in EMIS-2017 (38.6\%) [5].

In terms of morbidities, anxiety and depression were more prevalent among EMIS2017 participants in Greece than in Europe overall (61.6\% versus 52\%). Nevertheless, the severe anxiety/depression score was relatively lower (9\%) compared to that of other countries (16\%) [5]. HIV prevalence was relatively high $(11 \%)$ given that HIV prevalence in EMIS-2017 countries ranged from 3\% to 16\%. Lower prevalence than in the entire EMIS-2017 population was found for syphilis (9\% versus $14.2 \%)$, gonorrhea $(12.4 \%$ versus $19.2 \%$ ), and chlamydia (3.6\% versus $13.9 \%$ ). These findings are in accordance with the lower diagnosis rate of STIs in Greece compared to other European countries [16-18]. Of course, variability in testing policies and reporting patterns rather than different incidence rate of STIs may explain the abovementioned differences between Greece and other European countries. Regarding behaviors, there was a very low number of MSM in Greece who had ever tried to get $(2.2 \%)$ or use $(1 \%)$ PrEP, and about $40 \%$ of participants had been vaccinated against hepatitis $\mathrm{A}$ or $\mathrm{B}$.

Many participants were unaware of important information with respect to HIV chemoprophylaxis and transmission, and regarding vaccination against hepatitis $\mathrm{A}$ and hepatitis $B$ viruses. A significant percentage of participants were unaware of PEP (33.9\%) or PrEP (41.2\%) in accordance with other EMIS-2017 countries [5]. The relative low awareness for PrEP in Greece could be due to the fact that PrEP has not been administered in Greece yet. It was available only for participants of an implementation program named SOPHOCLESP4G [19]. It is anticipated that the awareness of PEP or PrEP perhaps increased after EMIS-2017, mostly due to significant efforts of non-governmental organizations, and especially of those of HIV-positive people (Positive voice) and of checkpoints.

More than half of the participants had experienced verbal violence at least once in their lives and one in five had faced physical violence. This high rate of verbal or physical aggression could perhaps explain, to some degree, why a substantial number of EMIS-2017 participants in Greece reported low outness and suicidal or self-destructive thoughts [20-22]. The vast majority of the participants (85.3\%) reported that no-one had spoken to them about PrEP and when they received information, this was primarily through checkpoints. The latter finding highlights the important role of checkpoints in surveillance and prevention [23].

The results presented in this report are subject to the limitations of anonymous, selfcompleted, online, cross-sectional surveys as EMIS-2017. Data validity can be influenced by multiple submissions by one person and the uncertainty about whether the participant providing answers actually met the inclusion criteria of EMIS-2017. The absence of an interviewer may induce differences in interpretations of survey questions and answer options among the participants. Potential limited access and reduced ability to use technology are common disadvantages of online surveys that decrease the ability to generalize. Recall bias and social desirability bias also have to be taken into account. The sample was large but convenient as many participants were recruited from social media websites and online applications and were thus probably non-representative of all MSM. The comparison of the EMIS-2010 sample with a nationally representative sample of MSM in the UK showed that younger, gay MSM and those who are more sexually active were overrepresented [24]. Nevertheless, EMIS-2017 provides essential baseline information and gives the opportunity to assess important needs. In particular, EMIS-2017 can significantly benefit HIV and viral hepatitis prevention programs. 


\section{Conclusions}

The results could be generalized to MSM who are able to use technology, have access to the internet, and are probably users of social media websites and certain online applications. HIV prevalence in that population was considerable, and a significant number of participants were not aware of a major prevention tool such as PrEP, which, however, was not available in Greece at the time.

Supplementary Materials: The following are available online at https:/ /www.mdpi.com/2673-3 986/2/1/10/s1, Figure S1: Age in years in the EMIS-2017 sample in Greece, Figure S2: Recency of using selected substances, Table S1: Education, current occupation/work status, and feelings about current income, Table S2: Sexual attraction, sexual identity, and outness, Table S3: Percentages of current partnerships, type of partnership, and when the last steady partnership broke up, Table S4: Buying and selling sex, Table S5: Mental health. Men were asked to report how often they had been bothered by the following problems, over the last two weeks, Table S6: Alcohol dependency, Table S7: Sex with non-steady male partners and condom use in the last 12 months, Table S8: Sex under intoxication, Table S9: Self-efficacy measures considering sex, Table S10: HIV transmission, testing and treatment knowledge, Table S11: Post-exposure prophylaxis (PEP) and pre-exposure prophylaxis (PrEP) knowledge, Table S12: Hepatitis knowledge and knowledge of where to get hepatitis A and B vaccinations among men who could benefit from hepatitis A and B vaccine, Table S13: Homophobic abuse: intimidation, insults, and violence, Table S14: Sources of condoms in the last 12 months and most common source, Table S15: Recency of seeing/hearing any information about HIV or STIs specifically for men who have sex with men, Table S16: Satisfaction with support and information received during HIV testing.

Author Contributions: EMIS-2017 survey design, implementation, and coordination, A.J.S.; Methodology, G.K.N.; formal analysis, K.P. and G.K.N.; investigation, K.P., G.T., S.C., G.P. (Georgios Polkas), G.P. (Georgios Papageorgiou), N.D., and G.K.N.; data curation, K.P. and G.K.N.; writing-original draft preparation, K.P.; writing—review and editing, G.T., S.C., G.P. (Georgios Polkas), G.P. (Georgios Papageorgiou), N.D., A.J.S., and G.K.N.; supervision, A.J.S. and G.K.N. All authors have read and agreed to the published version of the manuscript.

Funding: EMIS-2017 was funded by the European Commission Health Programme 2014-2020 in the framework of the Third EU Health Programme (2014-2020) and supported by the following organizations: PlanetRomeo, European AIDS Treatment Group (EATG), Eurasian Coalition on Male Health (ECOM), European Centre for Disease Prevention and Control (ECDC), European Monitoring Centre for Drugs and Drug Addiction (EMCDDA), European Commission (DG SANTE).

Institutional Review Board Statement: The study was conducted according to the guidelines of the Declaration of Helsinki, and approved by the Observational Research Ethics Committee at the London School of Hygiene and Tropical Medicine (reference 14421/RR/8805) on 31 July 2017.

Informed Consent Statement: All participants in the internet survey were asked to confirm that they consent to participate.

Data Availability Statement: The data presented in this study may be available from the London School of Hygiene and Tropical Medicine upon reasonable request.

Acknowledgments: We thank all men who filled in the survey. We thank PlanetRomeo for supporting EMIS-2017. We thank the following organizations for their advice: European AIDS Treatment Group (EATG), Eurasian Coalition on Male Health (ECOM), European Centre for Disease Prevention and Control (ECDC), European Monitoring Centre for Drugs and Drug Addiction (EMCDDA), and European Commission (DG SANTE).

Conflicts of Interest: The authors declare no conflict of interest. The funders had no role in the design of the study; in the collection, analyses, or interpretation of data; in the writing of the manuscript, or in the decision to publish the results. 


\section{References}

1. World Health Organization. HIV/AIDS: Key Facts. 2020. Available online: https://www.who.int/news-room/fact-sheets/ detail/hiv-aids (accessed on 14 October 2020).

2. World Health Organization. Men Who Have Sex with Men (MSM); WHO: Geneva, Switzerland, 2019; Available online: https:/ / www.euro.who.int/en/health-topics/communicable-diseases/hivaids/policy/policy-guidance-for-key-populationsmost-at-risk2/men-who-have-sex-with-men-msm (accessed on 14 October 2020).

3. Scott-Sheldon, L.A.J.; Chan, P.A. Increasing sexually transmitted infections in the U.S.: A call for action for research, clinical, and public health practice. Arch. Sex. Behav. 2019, 49, 13-17. [CrossRef] [PubMed]

4. Werner, R.N.; Gaskins, M.; Nast, A.; Dressler, C. Incidence of sexually transmitted infections in men who have sex with men and who are at substantial risk of HIV infection-A meta-analysis of data from trials and observational studies of HIV pre-exposure prophylaxis. PLoS ONE 2018, 13, e0208107. [CrossRef] [PubMed]

5. The EMIS Network. EMIS-2017: The European Men-Who-Have-Sex-With-Men Internet Survey; European Centre for Disease Prevention and Control: Stockholm, Sweden, 2019. Available online: www.emis2017.eu (accessed on 23 February 2021).

6. Sigma Research. EMIS-2017: European MSM Internet Survey. 2017. Available online: www.emis2017.eu (accessed on 15 October 2020).

7. Sigma Research. Questionnaires: EMIS-2017. 2017. Available online: http://sigmaresearch.org.uk/questionnaires/tags/tag/ EMIS-2017 (accessed on 15 October 2020).

8. Weatherburn, P.; Hickson, F.; Reid, D.S.; Marcus, U.; Schmidt, A.J. European men-who-have-sex-with-men internet survey (EMIS-2017): Design and methods. Sex. Res. Soc. Policy 2013, 10, 243-257. [CrossRef]

9. Hellenic Statistical Authority. Demographic Characteristics. 2011. Available online: https://www.statistics.gr/en/statistics/pop (accessed on 28 September 2020).

10. Nikolopoulos, G.K.; Sypsa, V.; Bonovas, S.; Paraskevis, D.; Malliori-Minerva, M.; Hatzakis, A.; Friedman, S.R. Big events in greece and HIV infection among people who inject drugs. Subst. Use Misuse 2015, 50, 825-838. [CrossRef] [PubMed]

11. Hellenic Center for Disease Control and Prevention. HIV/AIDS Surveillance in Greece, 31 December 2017. 2018. Available online: https:/ / eody.gov.gr/wp-content/uploads/2018/12/epidimiologiko-deltio-hiv-2018.pdf (accessed on 23 February 2021).

12. EMIS 2017. Variable Manual. 2017. Available online: http://sigmaresearch.org.uk/files/EMIS-2017-Variable-Manual.pdf (accessed on 14 October 2020).

13. The EMIS Network. EMIS 2010: The European Men-Who-Have-Sex-With-Men Internet Survey. Findings from 38 Countries; European Centre for Disease Prevention and Control: Stockholm, Sweden, 2013; Available online: www.emis2017.eu (accessed on 23 February 2021).

14. Kroenke, K.; Spitzer, R.; Williams, J.; Löwe, B. An ultra-brief screening scale for anxiety and depression: The PHQ-4. Psycho Somat. 2009, 50, 613-621.

15. Mayfield, D.; McLeod, G.; Hall, P. The CAGE questionnaire: Validation of a new alcoholism screening instrument. Am. J. Psychiatry 1974, 131, 1121-1123. [PubMed]

16. European Centre for Disease Prevention and Control. Chlamydia Infection. Annual Epidemiological Report for 2018; European Centre for Disease Prevention and Control: Stockholm, Sweden, 2020. Available online: https://www.ecdc.europa.eu/en/publicationsdata/chlamydia-infection-annual-epidemiological-report-2018 (accessed on 23 February 2021).

17. European Centre for Disease Prevention and Control. Gonorrhoea. Annual Epidemiological Report for 2018; European Centre for Disease Prevention and Control: Stockholm, Sweden, 2020. Available online: https:/ /www.ecdc.europa.eu/en/publicationsdata/gonorrhoea-annual-epidemiological-report-2018 (accessed on 23 February 2021).

18. European Centre for Disease Prevention and Control. Syphilis. Annual Epidemiological Report for 2018; European Centre for Disease Prevention and Control: Stockholm, Sweden, 2020. Available online: https:/ /www.ecdc.europa.eu/en/publicationsdata/syphilis-annual-epidemiological-report-2018 (accessed on 23 February 2021).

19. Global Advocacy for HIV Prevention. Sophocles-P4G. Available online: https://www.avac.org/trial/sophocles-p4g (accessed on 22 January 2021).

20. King, M.; Semlyen, J.; Tai, S.S.; Killaspy, H.; Osborn, D.; Popelyuk, D.; Nazareth, I. A systematic review of mental disorder, suicide, and deliberate self harm in lesbian, gay and bisexual people. BMC Psychiatry 2008, 8, 70. [CrossRef] [PubMed]

21. O'Donnell, S.; Meyer, I.H.; Schwartz, S. Increased risk of suicide attempts among black and latino lesbians, gay men, and Bisexuals. Am. J. Public Health 2011, 101, 1055-1059. [CrossRef] [PubMed]

22. Paul, J.P.; Catania, J.; Pollack, L.; Moskowitz, J.; Canchola, J.; Mills, T.; Binson, D.; Stall, R. Suicide Attempts Among Gay and Bisexual Men: Lifetime Prevalence and Antecedents. Am. J. Public Health 2002, 92, 1338-1345. [CrossRef] [PubMed]

23. Nikolopoulos, G.K.; Chanos, S.; Tsioptsias, E.; Hodges-Mameletzis, I.; Paraskeva, D.; Dedes, N. HIV incidence among men who have sex with men at a community-based facility in Greece. Cent. Eur. J. Public Health 2019, 27, 54-57. [CrossRef] [PubMed]

24. Prah, P.; Hickson, F.; Bonell, C.; McDaid, L.M.; Johnson, A.M.; Wayal, S.; Clifton, S.; Sonnenberg, P.; Nardone, A.; Erens, B.; et al. Men who have sex with men in Great Britain: Comparing methods and estimates from probability and convenience sample surveys. Sex. Transm. Infect. 2016, 92, 455-463. [CrossRef] [PubMed] 